\title{
Expression of adhesion molecules on synovial fluid and peripheral blood monocytes in patients with inflammatory joint disease and osteoarthritis
}

\author{
M Köller, M Aringer, H Kiener, L Erlacher, K Machold, G Eberl, A Studnicka-Benke, \\ W Graninger, J Smolen
}

\begin{abstract}
Objective-To determine the presence of adhesion molecules on monocytes/ macrophages $(M \phi)$ from peripheral blood (PB) and synovial fluid (SF) in patients with osteoarthritis (OA) and inflammatory joint diseases (rheumatoid (RA) and reactive arthritis $(\operatorname{Re} A)$ ) in order to improve our understanding of the possible mechanisms underlying the inflammatory process.

Methods-Whole blood and SF cells were stained with monoclonal antibodies against CD11a (LFA-1), CD15 s (sialylLewis X), CD44, CD54, VLA-4, and HLA-DR counterstained with anti-CD14 antibodies as a $M \phi$ marker for dual fluorescence analysis by flowcytometry.

Results-On PB-M $\phi$, CD15s was markedly increased in both RA as well as ReA compared with OA. Furthermore, in the PB LFA-1, CD44, and HLA-DR showed a higher surface density on $M \phi$ in $\operatorname{ReA}$ than in OA. Comparison between SF and PB showed significantly higher CD44 and CD54 expression on SF-M $\phi$. These molecules play an important part in lymphocyte-M $\phi$ interaction.

Conclusion-In PB from patients with inflammatory joint diseases, $M \phi$ are activated, allowing recruitment into the synovial compartment. These disorders, in contrast with $\mathrm{OA}$ seem to be "systemic" in nature. Within the SF, different adhesion molecules are expressed on $\mathrm{CD}_{1}{ }^{+} \mathrm{M} \phi$ as compared with PB.

(Ann Rheum Dis 1999;58:709-712)
\end{abstract}

A hallmark of arthritic conditions is the accumulation of leucocytes within the synovial fluid (SF). Among those, cells of the monocyte/ macrophage $(M \phi)$ lineage play an important part ${ }^{1}$ and are thought to be involved in the pathogenesis of inflammatory joint diseases. ${ }^{2}$

Mechanisms of cell migration via endothelial cells (EC) into areas of inflammation are increasingly understood. A variety of adhesion molecules and their functions have been partly elucidated in recent years. In respect to $M \phi$, differences in certain function associated and differentiation associated molecules have been shown to exist between SF-M $\phi$ and peripheral blood (PB)-M $\phi$ from patients with rheumatoid arthritis (RA), reactive arthritis $(\operatorname{ReA})$ and osteoarthritis (OA). ${ }^{34}$
In this investigation we intended to elucidate the type and distribution of adhesion molecules on PB-M $\phi$ and SF-M $\phi$ as well as possible differences between patients with different diseases.

\section{Methods}

PATIENTS

Arthrocentesis of knee joint effusions was performed for therapeutic or diagnostic purposes. No intra-articular injection of hyaluronate or corticosteroids was evident within the past six months. SF samples were obtained in heparinised tubes from 20 patients with inflammatory arthritis (IA), namely $10 \mathrm{RA}$ (diagnosed according to the ACR criteria ${ }^{5}$ ) and $10 \mathrm{ReA}$ (diagnosed as previously described ${ }^{6}$ ), as well as 10 patients with OA. ${ }^{7}$ All SF were analysed microscopically and crystal induced arthritides ruled out; in parallel PB was collected in heparinised tubes on the occasion of routine laboratory testing. Informed consent was obtained from all patients. Table 1 shows the patient characteristics.

IMMUNOFLUORESCENCE AND FLOW CYTOMETRY Staining of PB-M $\phi$ was performed in whole blood for 30 minutes at room temperature. ${ }^{8}$ SF cells were pelleted by centrifugation and resuspended in phosphate buffered saline (PBS) containing 3\% bovine serum albumin (BSA). To avoid cell activation of these samples, $0.1 \%$ sodium azide $\left(\mathrm{Na}_{3} \mathrm{~N}\right)$ was added and probes were kept at room temperature. To remove clots, cell suspensions were filtered through a Cell Strainer 2350 (Falcon, Lincoln Park, NJ). In all experiments $10^{7}$ cells were stained in $100 \mu \mathrm{l} \mathrm{PBS} / \mathrm{BSA} / \mathrm{Na}_{3} \mathrm{~N}$, containing murine monoclonal antibodies (mab) in predetermined optimal concentrations. Cells were stained with mabs against leucocyte function antigen-1 (LFA-1; CD11a), sialyl Lewis X (sLeX; CD15s), hyaluronic acid receptor (CD44), intercellular adhesion molecule-1 (ICAM-1; CD54), very late activation antigen-4 (VLA-4; CD49d), and MHC-class II (HLA-DR). All mabs were purchased from Becton Dickinson, San Jose, CA, USA, except anti-CD54 (Immunotech, Marseille, France). Mabs were labelled with fluoro-iso-thiocyanate (FITC), except antiCD15s and anti-VLA-4 (both CAMFolio, Becton Dickinson). Binding of unconjugated mabs was visualised with a rabbit-antimouse IgG mab (FITC labelled, Dako, Glostrup, Denmark). For direct immunofluorescence 
Table 1 Patient characteristics

\begin{tabular}{|c|c|c|c|c|c|c|c|c|c|c|}
\hline $\operatorname{Sex}$ & Age & $E S R$ & $C R P$ & $R F$ & $S F-W B C$ & PB-MO abs/rel & & & & \\
\hline \multicolumn{11}{|c|}{ Osteoarthritis } \\
\hline $\mathrm{f}$ & 59 & 13 & 0.5 & neg & 2000 & $425 / \mu \mathrm{l} ; 3.0 \%$ & & & & \\
\hline $\mathrm{m}$ & 78 & 10 & 0.5 & neg & 1600 & $302 / \mu 1 ; 2.9 \%$ & & & & \\
\hline $\mathrm{m}$ & 70 & 16 & 0.2 & neg & 100 & $239 / \mu \mathrm{l} ; 2.7 \%$ & & & & \\
\hline $\mathrm{f}$ & 72 & 19 & 0.5 & neg & 3000 & $498 / \mu \mathrm{l} ; 3.9 \%$ & & & & \\
\hline $\mathrm{m}$ & 68 & 14 & 0.2 & neg & 1500 & $240 / \mu 1 ; 3.7 \%$ & & & & \\
\hline $\mathrm{m}$ & 70 & 18 & 0.3 & neg & 500 & $375 / \mu \mathrm{l} ; 5.5 \%$ & & & & \\
\hline $\mathrm{m}$ & 65 & 8 & 0.4 & neg & 1200 & $296 / \mu 1 ; 2.4 \%$ & & & & \\
\hline $\mathrm{m}$ & 58 & 12 & 0.3 & neg & 2500 & $371 / \mu \mathrm{l} ; 3.1 \%$ & & & & \\
\hline $\mathrm{f}$ & 73 & 14 & 0.6 & neg & 2800 & $441 / \mu 1 ; 3.5 \%$ & & & & \\
\hline $\mathrm{m}$ & 49 & 4 & 0.2 & neg & 100 & $601 / \mu 1 ; 6.1 \%$ & & & & \\
\hline \multicolumn{7}{|c|}{ Rheumatoid arthritis } & Duration & $D M A R D$ & NSAID & Corticosteroids \\
\hline f & 26 & 54 & 5.7 & pos & 14900 & $321 / \mu 1 ; 3.0 \%$ & 8 & MTX $12.5 \mathrm{mg} / \mathrm{wk}$ & none & none \\
\hline $\mathrm{f}$ & 48 & 72 & 10.1 & neg & 12000 & $595 / \mu 1 ; 6.3 \%$ & 1 & MTX $10 \mathrm{mg} / \mathrm{wk}$ & diclofenac $150 \mathrm{mg} / \mathrm{d}$ & none \\
\hline $\mathrm{f}$ & 85 & 90 & 12.4 & neg & 52000 & $870 / \mu 1 ; 7.5 \%$ & 19 & MTX $12.5 \mathrm{mg} / \mathrm{wk}$ & ketoprofen $200 \mathrm{mg} / \mathrm{d}$ & prednisolon $5 \mathrm{mg} / \mathrm{d}$ \\
\hline $\mathrm{m}$ & 55 & 80 & 5.1 & pos & 25000 & $490 / \mu 1 ; 6.3 \%$ & 3 & $\mathrm{SSZ} 2000 \mathrm{mg} / \mathrm{d}$ & ibuprofen $1800 \mathrm{mg} / \mathrm{d}$ & prednosolon $7.5 \mathrm{mg} / \mathrm{d}$ \\
\hline f & 77 & 20 & 3 & pos & 10600 & $298 / \mu l ; 3.1 \%$ & 2 & CQ $150 \mathrm{mg} / \mathrm{d}$ & diclofenac $150 \mathrm{mg} / \mathrm{d}$ & none \\
\hline $\mathrm{f}$ & 72 & 74 & 6.2 & neg & 18500 & $430 / \mu 1 ; 5.2 \%$ & 10 & MTX $15 \mathrm{mg} / \mathrm{d}$ & naproxen $1000 \mathrm{mg} / \mathrm{d}$ & prednosolon $10 \mathrm{mg} / \mathrm{d}$ \\
\hline $\mathrm{m}$ & 59 & 86 & 7 & pos & 8000 & $370 / \mu 1 ; 4.9 \%$ & 7 & SSZ $3000 \mathrm{mg} / \mathrm{d}$ & diclofenac $100 \mathrm{mg} / \mathrm{d}$ & none \\
\hline f & 79 & 54 & 3.3 & pos & 18100 & $435 / \mu 1 ; 3.1 \%$ & 1 & $\mathrm{SSZ} 2000 \mathrm{mg} / \mathrm{d}$ & indomethacin $100 \mathrm{mg} / \mathrm{d}$ & prednisolon $10 \mathrm{mg} / \mathrm{d}$ \\
\hline $\mathrm{m}$ & 71 & 42 & 5.8 & pos & 8200 & $910 / \mu \mathrm{l} ; 10 \%$ & 1 & none & diclofenac $150 \mathrm{mg} / \mathrm{d}$ & none \\
\hline $\mathrm{f}$ & 54 & 38 & 1.6 & neg & 7500 & $700 / \mu \mathrm{l} ; 11 \%$ & 2 & MTX $15 \mathrm{mg} / \mathrm{d}$ & indomethacin $100 \mathrm{mg} / \mathrm{d}$ & none \\
\hline \multicolumn{7}{|c|}{ Reactive arthritis } & Infection & $D M A R D$ & NSAID & Corticosteroids \\
\hline $\mathrm{m}$ & 26 & 20 & 2.3 & neg & 5000 & $540 / \mu 1 ; 5.2 \%$ & n.id. & none & none & none \\
\hline $\mathrm{m}$ & 46 & 46 & 1.1 & neg & 5500 & $398 / \mu 1 ; 5.4 \%$ & n.id. & none & diclofenac $100 \mathrm{mg} / \mathrm{d}$ & none \\
\hline f & 33 & 70 & 2 & neg & 19900 & $422 / \mu 1 ; 6.2 \%$ & Chlamydia & none & piroxicam $20 \mathrm{mg} / \mathrm{d}$ & none \\
\hline $\mathrm{m}$ & 32 & 40 & 2.2 & neg & 2200 & $500 / \mu \mathrm{l} ; 8 \%$ & n.id. & MTX $12.5 \mathrm{mg} / \mathrm{wk}$ & ketoprofen $300 \mathrm{mg} / \mathrm{d}$ & none \\
\hline f & 24 & 112 & 7.8 & neg & 29000 & $400 / \mu 1 ; 6 \%$ & Chlamydia & none & diclofenac $100 \mathrm{mg} / \mathrm{d}$ & none \\
\hline $\mathrm{m}$ & 40 & 79 & 4.3 & neg & 3300 & $1410 / \mu 1 ; 14 \%$ & Yersenia & $\mathrm{SSZ} 3000 \mathrm{mg} / \mathrm{d}$ & none & prednisolone $5 \mathrm{mg} / \mathrm{d}$ \\
\hline $\mathrm{m}$ & 47 & 34 & 2.2 & neg & 9000 & $250 / \mu \mathrm{l} ; 4.5 \%$ & n.id. & none & diclofenac $100 \mathrm{mg} / \mathrm{d}$ & none \\
\hline $\mathrm{f}$ & 28 & 48 & 2.1 & neg & 30000 & $560 / \mu 1 ; 7.5 \%$ & Chlamydia & none & none & none \\
\hline $\mathrm{m}$ & 46 & 34 & 2.4 & neg & 4000 & $880 / \mu \mathrm{l} ; 10 \%$ & n.id. & none & diclofenac $100 \mathrm{mg} / \mathrm{d}$ & methyl-pred. $8 \mathrm{mg} / \mathrm{d}$ \\
\hline $\mathrm{m}$ & 55 & 48 & 7.7 & neg & 19400 & $625 / \mu l ; 5.5 \%$ & n.id. & none & ibuprofen $1200 \mathrm{mg} / \mathrm{d}$ & none \\
\hline
\end{tabular}

Sex (m, male; f, female); age (y); ESR, erythrocyte sedimentation rate ( $\mathrm{mm} \mathrm{1st} \mathrm{h;} \mathrm{normal} \mathrm{<15);} \mathrm{CRP,} \mathrm{C} \mathrm{reactive} \mathrm{protein} \mathrm{(mg/dl,} \mathrm{normal} \mathrm{<0.5);} \mathrm{RF,} \mathrm{rheumatoid} \mathrm{factor;}$ SF-WBC, synovial fluid white blood cell count (leucocytes/ $\mu$ ); peripheral blood monocytes (PB-Mo); disease duration (y); infection (n.id.; not identified); disease modifying antirheumatic drug (DMARD: CQ, chloroquine; MTX, methotrexate; SSZ, sulfasalazine); non-steroidal anti-rheumatic drug (NSAID).

staining $\operatorname{IgG}_{1}$ and $\operatorname{IgG}_{2 \mathrm{a}}$ (FITC and phycoerythrin (PE) labelled, Simultest, BectonDickinson) were used as respective isotype controls. Unconjugated murine $\operatorname{IgG}_{2 \mathrm{~b}}$ (Dako) was the negative control in the indirect immunofluorescence assay. After two washing steps all samples were counterstained with an anti-CD14 mab (PE labelled, Leu-M3, Becton-Dickinson). To remove erythrocytes all cells were incubated with lysing solution (Becton-Dickinson) for 15 minutes at room temperature, which also leads to fixation of stained cells. Leucocytes were then pelleted and resuspended in $200 \mu \mathrm{l}$ PBS before analysis was performed with a flow cytometer (FACScan, Becton Dickinson). Five thousand $M \phi$ were acquired by gating for CD14 positive $\left(^{+}\right)$ cells. All results were expressed as mean fluorescence intensity (MFI). To ensure comparable flourescence data, alignment and instrument control were done daily by running Immunocheck beads (Coulter, Hileah, FL, USA) on the cytometer before data acquisition.

\section{STATISTICS}

Group data were obtained by calculating mean (SEM) MFI. Statistical analysis of differences was performed by Wilcoxon test. Data were analysed using StatWorks software running on an Apple Macintosh IIvx computer.

\section{Results}

PERIPHERAL BLOOD MONOCYTE COUNTS

Statistically significant higher absolute $(\mathrm{M} \phi / \mu \mathrm{l}$ $(\mathrm{SEM})$ ) and relative (\% of PB leucocytes (SEM)) monocyte counts in the PB have been found in patients with RA (542 (70); 6.0\% $(0.9 \%)$ ) and $\operatorname{ReA}(599(105) ; 7.2 \%(0.9 \%))$ than patients with OA (379 (37); 3.7\% (0.4\%)) (fig 1).

FLOW CYTOMETRY RESULTS

Table 2 shows the results of mean (SEM) MFI.

CARBOHYDRATE LIGAND RECEPTOR

sLeX (CD15s) expression was more than threefold higher on PB-M $\phi$ in both, RA $(p<0.05)$ and $\operatorname{ReA}(p<0.05)$ than in OA but comparable on SF-M $\phi$.

INTEGRINS

The surface density of LFA-1 (CD11a) tended to be higher on $\mathrm{PB}-\mathrm{M} \phi$ in RA (NS) patients than those with OA but only reached statistical significance in ReA patients $(\mathrm{p}<0.05)$. LFA-1 expression on SF-M $\phi$ was similar in all groups.

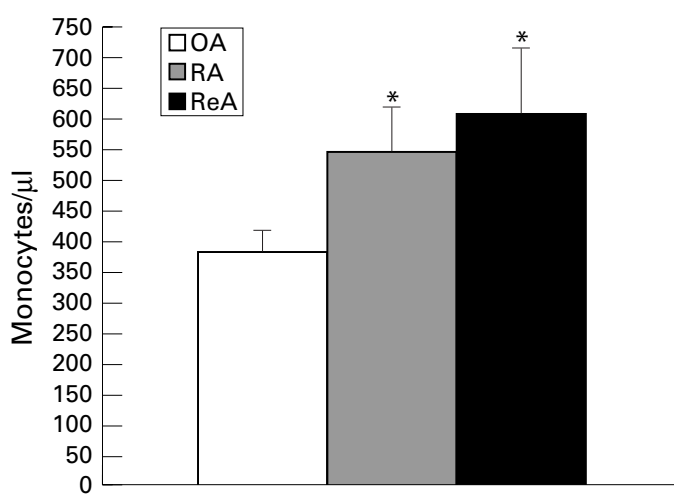

Figure 1 Absolute monocyte counts in the peripheral blood of patients with osteoarthritis $(O A)$, rheumatoid $(R A)$ and reactive arthritis (ReA) are shown. Columns represent mean (SD) values of monocytes/ $\mu$. 
Table 2 Expression of adhesion molecules on peripheral blood (PB) and synovial fluid (SF) $C D 14^{+}$monocytes of patients with osteoarthritis, rheumatoid and reactive arthritis. Values show mean (SEM) fluorescence intensity

\begin{tabular}{llll}
\hline & Osteoarthritis & Rheumatoid arthritis & Reactive arthritis \\
\hline sLeX (CD15s) & & & \\
PB & $109.0(22.6)$ & $431.0(60.3)^{\star}$ & $402.9(61.1)^{\star}$ \\
SF & $138.5(13.8)$ & $169.1(24.3)$ & $186.4(43.0)$ \\
LFA-1 (CD11a) & & & \\
PB & $210.9(7.5)$ & $250.5(21.7) \dagger$ & $340.2(12.3)^{\star}$ \\
SF & $189.7(9.4)$ & $213.6(21.3)$ & $194.5(7.8)$ \\
VLA-4 (CD49d) & & $76.2(9.6)$ & $90.7(5.0)$ \\
PB & $83.8(5.2)$ & $93.2(14.1) \dagger$ & $127.0(7.3)$ \\
SF & $122.6(5.3)$ & $47.6(9.4) \dagger$ & \\
ICAM-1 (CD54) & & $120.0(24.1) \dagger$ & $217.1(31.3)^{\star}$ \\
PB & $51.8(6.8)$ & $152.9(39.3)$ & $234.6(29.3)^{\star}$ \\
SF & $99.0(20.7)$ & $382.7(123.0)$ & $470.1(26.3)^{\star}$ \\
CD44 & $111.1(13.2)$ & $568.0(130.5)$ & $649.1(85.3)^{\star}$ \\
PB & $270.9(19.6)$ & $2003.8(389.8)^{\star}$ & $2233.0(136.5)^{\star}$ \\
SF & $343.8(80.1)$ & & \\
HLA-DR & $1079.5(187.0)$ & &
\end{tabular}

*Indicates statistically significant difference compared with OA patients. †Indicates statistically significant difference between RA and REA ( $\mathrm{p}<0.05)$

In general, VLA-4 (CD49d), which binds to endothelial VCAM-1, was found in similar amounts in all disease groups. It is only weakly expressed, on both, PB-M $\phi$ and SF-M $\phi$.

\section{IMMUNOGLOBULIN FAMILY}

No significant difference was seen regarding PB-M ICAM-1 (CD54) expression. The higher surface density on SF-M $\phi$ in inflammatory joint diseases was only significant in ReA patients $(p<0.05)$ when compared with OA

HOMING RECEPTOR

CD44 expression in ReA patients was higher than in OA on both, PB-M $\phi$ and SF-M $\phi$ $(\mathrm{p}<0.05)$, but no significant difference was seen between OA and RA.

MHC-CLASS II

$\mathrm{PB}-\mathrm{M} \phi$ from ReA patients had higher HLA-DR expression than those from OA patients $(p<0.05)$, but for RA the difference failed to be statistically significant. Among SF-M $\phi$, both, RA and ReA showed significantly higher surface levels than from OA $(\mathrm{p}<0.05)$.

\section{COMPARISON OF RA AND REA}

Adhesion molecule surface densities on M申 in ReA patients were comparable to or higher than those in RA patients. A significant difference was found in the SF concerning VLA-4 and ICAM-1. In the PB LFA-1 and ICAM-1 expressions were significantly higher in ReA patients. There were no differences in absolute and relative $\mathrm{PB}-\mathrm{M} \phi$ counts in patients with $\mathrm{RA}$ and $\operatorname{ReA}$ (fig 1).

COMPARISON OF PB-M $\Phi$ AND SF-M $\Phi$

Because of different technical isolation and staining procedures, a comparison of MFI values of M from the SF and the PB is of limited reliability. In all patients a surface density increase of the most adhesion molecules was detected in the SF compared with PB-M $\phi$ (CD44, ICAM-1, HLA-DR and VLA-4; $\mathrm{p}<0.05)$. Only CD15s on M $\phi$ from the SF is expressed to a lower extent than from the PB $(p<0.05)$. Moreover, this was only seen in patients with IA.

\section{Discussion}

The results obtained show differences in adhesion molecule expression on M $\phi$ in inflammatory, mainly ReA, as compared with degenerative joint diseases, but also on SF-M compared with PB-M $\phi$.

The different molecules are known to serve different functions. Thus, sLeX (CD15s) and its ligand ELAM-1 on endothelial cells (EC) are engaged in the initial phase of $M \phi$ adhesion. ${ }^{9}$ Patients with IA (both RA and ReA) had more than threefold higher levels of CD15s expression on circulating $M \phi$ than patients with OA. In SF, however, such an increase was not seen. Downregulation of sLeX after the migration into and through the synovial membrane is one hypothesis to explain the lower expression in the SF. Alternatively, soluble ELAM-1 released by activated EC might have masked the antigen on SF-M $\phi .^{10}$

LFA-1 (CD11a) interacts with endothelial ICAM-1 on EC, induces "stretching" of endothelium bound $M \phi$ and leads to transendothelial migration. ${ }^{9}$ Similar to CD15s, LFA-1 was higher on PB-M of patients with ReA than $\mathrm{OA}$ and showed such a tendency in RA. On SF-M comparable levels exist in all disease groups. Cytokines such as interferon (IFN) $\gamma$ have been demonstrated to downregulate surface LFA-1. The data on sLeX and LFA-1 suggest a systemic activation of $\mathrm{PB}-\mathrm{M} \phi$ in IA with possibly increased recruitment via binding to EC.

In contrast, VLA-4 (CD49d), which mediates "rolling" of leucocytes and is required by $M \phi$ for migration into the joint, ${ }^{911}$ was expressed to similar extents among $M \phi$ from patients with IA and OA, although there was a difference between RA and ReA patients, but was slightly higher on SF-M $\phi$ compared with PB-M $\phi$. The activated form of VLA-4 binds to the matrix component fibronectin. Thus, CD49d does not seem to exert its role in arthritis by changes in cell surface density. It is conceivable that conformational changes are more important for adhesive function.

CD44 was found in higher levels on SF-M $\phi$ compared with $\mathrm{PB}-\mathrm{M} \phi$ in all groups. Hyaluronate, which is found abundantly in the SF and binds to its receptor (CD44), can activate monocytes, induces monokine production, and regulates interleukin (IL) 1 and tumour necrosis factor (TNF) $\alpha$ production by $\mathrm{M} \phi .^{12} \mathrm{No}$ significant differences on $\mathrm{PB}-\mathrm{M} \phi$ and $\mathrm{SF}-\mathrm{M} \phi$ were found between patients with RA and OA, although CD44 tended to be higher in RA. In contrast, this difference reached statistical significance higher in patients with ReA when compared with the OA.

Interaction between $M \phi$ and lymphocytes is partly mediated by ICAM-1 (CD54). This molecule was expressed to higher degrees on $\mathrm{M} \phi$ in the SF of patients with arthritis. Therefore SF-M may intimately interact with $T$ cells, which are known to express high levels of LFA-1. ${ }^{13}$ This circumstance is further substantiated by the increase in HLA-DR expression on both SF-M in arthritis patients. All these changes can be induced by cytokines, such as interleukin IL4, IFN $\gamma$ or TNF $\alpha .{ }^{9}{ }^{14}$ 
Patients with RA showed lower expressions of some adhesion (LFA-1, ICAM-1, VLA-4) molecules as compared with patients with ReA. RA patients had a longer intake and higher dose of anti-rheumatic drugs than ReA patients. Non-steroidal anti-inflammatory drugs have been shown to influence adhesion molecule expression, which probably contributes to these differences. ${ }^{15}$ This may also cause the lack of some significant differences in the RA group when compared with OA. Interestingly, there have been comparable absolute and relative $\mathrm{PB}$ monocyte counts in $\mathrm{RA}$ and $\mathrm{ReA}$ patients.

Taken together, the data indicate that $\mathrm{CD} 14^{+}$ $\mathrm{M} \phi$ from the PB of patients with inflammatory joint disease are activated to a state that enables binding to EC and transendothelial migration (CD11a and CD15s). Furthermore, M from the SF seem to express highly some of the adhesion molecules that are needed for interaction with T cells (ICAM-1, HLA-DR) reflecting their propensity for intensive interaction with cognate immunocompetent cells. Interestingly, under both, degenerative and inflammatory conditions SF-M $\phi$ show higher surface density of receptors for connective tissue constituents (CD44) than PB cells.

All these observations substantiate the importance of the upregulated adhesion molecules on $M \phi$ in the pathogenesis of IA, but they only provide data on surface expression of these function associated molecules. Further analysis of migratory capacity of $M \phi$ will be needed to prove the above assumptions; however these assumptions are based on known effects of these molecules. Our data also indicate that therapeutic approaches leading to downregulation of these molecules may be of significant interest.

Finally, it should be borne in mind that our results relate to $\mathrm{CD} 14^{+}$cells. CD14 is expressed by only a part of the M $\phi$ lineage. ${ }^{16} \mathrm{M} \phi$ may also be activated in other compartmentsthat is, the bone marrow or the synovial membrane before they enter the sites investigated here (PB, SF). Thus, additional studies will also have to focus also on other functional populations.

1 Cutolo M, Sulli A, Barone A, Seriolo B, Accardo S. Macrophages, synovial tissue, and rheumatoid arthritis. Clin Exp Rheumatol 1993;11:331-9.

2 Burmester GR, Stuhlmüller B, Keyszer G, Kinne RW Mononuclear phagocytes and rheumatoid synovitis. Arthritis Rheum 1997;40:5-18.

3 Gadd SJ, Felzmann T, Majdic O, Maurer D, Petera P, Chen WJ, et al. Phenotypic analysis of functionally associated molecules on peripheral blood and synovial fluid monocytes from arthritis patients. Rheumatol Int 1992;12: 153-7.

4 Lioté F, Boval Boizard B, Weill D, Kuntz D, Wautier JL. Blood monocyte activation in rheumatoid arthritis: increased monocyte adhesiveness, integrin expression, and cytokine release. Clin Exp Immunol 1996;106:13-19.

5 Arnett FC, Edworthy SM, Bloch DA, McShane DJ, Fries JF, Cooper NS, et al. The American Rheumatism Associa$\mathrm{JF}$, Cooper NS, et al. The American Rheumatism Associa-
tion 1987 revised criteria for the classification of rheumation 1987 revised criteria for the classification of
toid arthritis. Arthritis Rheum 1988;31:315-24.

toid arthritis. Arthritis Rheum 1988;31:315-24.
6 Erlacher L, Wintersberger W, Menschik M, BenkeStudnicka A, Machold K, Stanek G, et al. Reactive arthritis: urogenital swab culture is the only useful diagnostic method for the detection of the arthritogenic infection in extra-articularly asymptomatic patients with undifferentiated oligoarthritis. Br J Rheumatol 1995;34:838-42.

7 Altman R, Asch E, Bloch D, Bole G, Borenstein D, Brandt $\mathrm{K}$, et al. Development of criteria for the classification and reporting of osteoarthritis. Arthritis Rheum 1986;29:103949.

8 Youssef PP, Mantzioris BX, Roberts-Thomson PJ, Ahern MJ, Smith MD. Effects of ex vivo manipulation on the expression of cell adhesion molecules on neutrophils. J Immunol Methods 1995;186:217-24.

9 Beekhuizen H, van Furth R. Monocyte adherence to human vascular endothelium. J Leukoc Biol 1993;54:363-78.

10 Leeuwenberg JFM, Smeets EF, Neefjes JJ, Shaffer MA Cinek T, Jeunhomme TM, et al. E-selectin and intercellular adhesion molecule-1 are released by activated endothelial cells in vitro. Immunology 1992;77:543-9.

11 Issekutz AC, Issekutz TB. Monocyte migration to arthritis in the rat utilizes both CD11/CD18 and very late activation antigen 4 integrin mechanisms. J Exp Med 1995;181: 1197-203.

12 Webbs DS, Shimizu Y, Van Seventer GA, Sahw S, Gerrard TL. LFA-3, CD 44, and CD 45: physiologic triggers of human monocyte TNF and IL-1 release. Science 1990; 249:1295-7.

13 Neumayer HP, Schultz TF, Peters JH, Dierich MP. Importance of ICAM-1 for accessory cell function of monocytic cells. Immunobiol 1990;180:458-66.

14 Tormey VJ, Faul J, Leonard C, Burke CM, Dilmec A, Poulter LW. T-cell cytokines may control the balance of functionally distinct macrophage populations. Immunology 1997;90:463-9.

15 Garcia Vicuna R, Diaz Gonzalez F, Gonzalez Alvaro I, del Pozo MA, Mollinedo F, Cabanas C, et al. Prevention of cytokine induced changes in leukocyte adhesion receptors by nonsteroidal antiinflammatory drugs from the oxicam family. Arthritis Rheum 1997;40:143-53.

16 Ziegler-Heitbrock HWL, Ulevtich RJ. CD14: Cell surface receptor and differentiation marker. Immunol Today 1993; 14:121-5. 